\title{
Evaluation of new selective culture media and a rapid fluorescence in situ hybridization assay for identification of Clostridium difficile from stool samples
}

\author{
Kathrin Bloedt, ${ }^{1}$ Melanie Riecker, ${ }^{1}$ Sven Poppert ${ }^{2}$ \\ and Nele Wellinghausen ${ }^{1,3}$ \\ ${ }^{1}$ Institute of Medical Microbiology and Hygiene, University Hospital of Ulm, Ulm, Germany \\ ${ }^{2}$ Department of Molecular Parasitology, Bernhard Nocht Institute for Tropical Medicine, Hamburg, \\ Germany \\ ${ }^{3}$ Dr Gaertner \& Partner Laboratories, Ravensburg, Germany
}

\begin{abstract}
Nele Wellinghausen
nele.wellinghausen@labor-

gaertner.de
\end{abstract}

Received 23 January 2009

Accepted 10 March 2009
Two new Clostridium difficile-selective agars, from Oxoid (according to Brazier) and from BD, were compared with cycloserine-cefoxitin-fructose agar (Oxoid) for their sensitivity of recovery of toxigenic $C$. difficile from stool samples. For the culture-positive samples, the sensitivities were 84.0, 42.6 and $90.4 \%$, respectively. In addition, a C. difficile-specific fluorescence in situ hybridization assay was developed, facilitating rapid and reliable identification of cultured isolates.

\section{INTRODUCTION}

Clostridium difficile-associated disease (CDAD) is increasingly recognized in both health-care facilities and community settings worldwide (Blossom \& McDonald, 2007; Burckhardt et al., 2008; Kuijper et al., 2006, 2007). Recently, a highly virulent $C$. difficile strain, referred to as North American pulsed-field type 1 and PCR ribotype 027 (NAP1/BI/027), has emerged that causes outbreaks and is associated with increased morbidity and mortality (Kuijper et al., 2006, 2007; McDonald et al., 2005). The diagnosis of CDAD is based mainly on a clinical picture of diarrhoea in patients with a history of recent antibiotic usage and laboratory tests targeting the bacterium or its toxins. Faecal toxin detection by cell cytotoxicity neutralization assay (CCNA) is still regarded as the gold standard for detection of CDAD. However, CCNA has a turnaround time of up to 3 days, is labour-intensive and requires facilities for cell culture. Detection of $C$. difficile by culture is performed infrequently (Barbut et al., 2003), possibly due to the high work load, a turnaround time of several days for identification and confirmation of toxin production in cultured isolates (toxigenic culture) (Blossom \& McDonald, 2007; Brazier, 1998), and associated costs. Toxigenic isolates have, however, been detected by culture in CCNA-negative stool samples (Delmee et al., 2005; Fenner et al., 2008; Gerding et al., 1986; Reller et al., 2007), indicating the high sensitivity of

Abbreviations: CCNA, cell cytotoxicity neutralization assay; CDAD, Clostridium difficile-associated disease; FISH, fluorescence in situ hybridization. culture. The emergence of new and highly virulent $C$. difficile strains has further stressed the importance of stool culture (Blossom \& McDonald, 2007; Delmee et al., 2005; Kuijper et al., 2006), as culture is the prerequisite for epidemiological investigations including strain typing and antimicrobial resistance testing. For culture of $C$. difficile, pre-reduced cycloserine-cefoxitinfructose agar (CCFA) with a high cycloserine concentration $\left(0.5 \mathrm{~g} \mathrm{l}^{-1}\right)$, as proposed by George and others, is the most widely used medium (Brazier, 1998; George et al., 1979; Mundy et al., 1995; Peterson et al., 1996). However, intense growth of stool flora is frequently observed, making detection and isolation of $C$. difficile difficult. Recently, new selective media for the detection of $C$. difficile in stool samples have been brought to market in Europe.

The aim of this study was to establish a fast and sensitive approach for the toxigenic culture of $C$. difficile from stool samples. Therefore, we evaluated two new selective agars, the modified $C$. difficile Selective Agar according to Brazier (1993) (CDSB) from Oxoid and the C. difficile Selective Agar (CDSA) from BD, in comparison with standard CCFA (Oxoid) for the detection of $C$. difficile. The toxicity of the isolates was confirmed by real-time PCR for the detection of the toxin B gene (van den Berg et al., 2005). For identification of suspected isolates, a newly designed rapid fluorescence in situ hybridization (FISH) assay was compared with two commercial biochemical tests, the API ID32A (bioMérieux; interpreted by Apiweb) and the RapID ANAII (Oxoid), and with 16S rRNA gene sequencing as the gold standard. 


\section{METHODS}

Faecal samples and media. Faecal samples from unselected patients of the University Hospital of Ulm for whom there was a request for C. difficile diagnosis between February and April 2008 were included in the study (407 samples from 211 patients, comprising 50 samples from 20 children and 357 samples from 191 adults). All but one of the faecal samples were diarrhoeic (loose or watery). CDAD was not epidemic in the hospital. Further clinical data from the patients were not available. Stool samples were homogenized manually if necessary and $10 \mu \mathrm{l}$ of each sample was plated semiquantitatively on pre-reduced CCFA, CDSA and CDSB plates within $4 \mathrm{~h}$ of arrival at the laboratory. CCFA contains cefoxitin $\left(0.016 \mathrm{~g} \mathrm{l}^{-1}\right)$ and cycloserine $\left(0.5 \mathrm{~g} \mathrm{l}^{-1}\right)$ for selection, fructose $\left(6.0 \mathrm{~g} \mathrm{l}^{-1}\right)$ and $7 \%$ horse blood. CDSA is a bloodless agar that contains cefoxitin $(0.016 \mathrm{~g}$ $\left.\mathrm{1}^{-1}\right)$, cycloserine $\left(0.25 \mathrm{~g} \mathrm{l}^{-1}\right)$ and neutral red $\left(0.03 \mathrm{~g} \mathrm{l}^{-1}\right)$ for selection, and mannitol $\left(6.0 \mathrm{~g} \mathrm{l}^{-1}\right)$ instead of fructose. CDSB contains cefoxitin $\left(0.008 \mathrm{~g} \mathrm{l}^{-1}\right)$, cycloserine $\left(0.25 \mathrm{~g} \mathrm{l}^{-1}\right)$, amphotericin $\left(0.008 \mathrm{~g} \mathrm{l}^{-1}\right)$ and neutral red $\left(0.03 \mathrm{~g} \mathrm{l}^{-1}\right)$ for selection, cholic acid $\left(1.0 \mathrm{~g} \mathrm{l}^{-1}\right)$, glucose $\left(1.0 \mathrm{~g}^{-1}\right)$ and $1 \%$ horse blood. In addition, $p$-hydroxyphenylacetate $\left(1.0 \mathrm{~g} \mathrm{l}^{-1}\right)$ potentiates the typical odour of $C$. difficile, and egg yolk (4\%) allows detection of lecithinase in clostridial species other than C. difficile.

Culture. Pre-treatment of stool samples by heat or alcohol shock can diminish competing flora but requires additional working steps and has not been confirmed to increase the sensitivity of culture (Brazier, 1998). Therefore, we refrained from performing heat or alcohol shock pre-treatment. Plates were incubated in an anaerobic jar for a minimum of $72 \mathrm{~h}$. In samples inspected daily during the first 3 days, $C$. difficile was detected on day 3 in $13.1 \%$ of plates. Colonies with a typical morphology (grey, flat, dry, spreading colonies) and/or a 'horse barn' odour were regarded as suspicious for $C$. difficile and were subcultured on Columbia blood agar for further identification and toxin detection. The number of $C$. difficile colonies, as well as the concomitant growth of stool flora, were grouped into four categories: very rare $(<10$ colonies), rare (present in first streak only), many (present in second streak) and abundant (present in third streak).

tcdB gene detection and 165 rRNA sequencing. The presence of the $t c d B$ gene in $C$. difficile was determined on a LightCycler by using primers 398CLDs and 399CLDas and a TaqMan probe according to van den Berg et al. (2005). Sequencing of a $386 \mathrm{bp}$ fragment of the 16S rRNA gene by primers DG74/RW01 (Greisen et al., 1994) was performed as gold standard.

FISH. For FISH, we designed a C. difficile-specific 16S rRNA-based probe (Cd-198 m: 5'-CATCCTGTACTGGCTCAC), labelled with Cy3 (Thermo Hybaid), and used it in conjunction with the eubacterial FITC-conjugated probe EUB (Amann et al., 1990). The probe was evaluated with a panel of reference strains (Table 1), and a homology search of the ARB and GenBank databases confirmed specificity of the probe for $C$. difficile. A minimum of one colony was applied to a glass slide, air dried and fixed for $10 \mathrm{~min}$ in $98 \%$ methanol. Afterwards, bacteria were lysed for $3 \mathrm{~min}$ at $46{ }^{\circ} \mathrm{C}$ in Tris/HCl buffer (ph 6.8) containing $1 \mathrm{mg}$ lysozyme (Sigma) $\mathrm{ml}^{-1}$ and $2 \mu \mathrm{g}$ lysostaphin (Sigma) $\mathrm{ml}^{-1}$ and fixed again for $3 \mathrm{~min}$ in $100 \%$ ethanol. Hybridization was performed in a slide heater at $46{ }^{\circ} \mathrm{C}$ for $10 \mathrm{~min}$, using $40 \%$ formamide in the hybridization buffer and corresponding salt concentrations in the washing buffer (Manz et al., 1992). Slides were investigated directly under a fluorescence microscope. Only regular, rod-shaped bacteria showing green fluorescence with the EUB probe and red fluorescence with the C. difficile-specific probe $\mathrm{Cd}-198 \mathrm{~m}$ were determined as positive.

\section{RESULTS AND DISCUSSION}

Out of the 407 stool samples, C. difficile was detected in 99 samples $(24.3 \%)$ by culture on at least one of the agars being tested, and 94 of these 99 isolates (from 45 patients including 16 samples from eight children with a mean age of 4 years) were toxigenic, i.e. the toxB gene was detected in the isolate. Overall, $C$. difficile was cultured in 85/94 samples $(90.4 \%)$ on CCFA. CDSB culture was positive in $79 / 94(84.0 \%)$ samples and CDSA culture in 40/94 $(42.6 \%)$ samples. A combination of CCFA and CDSB alone would have detected all culture-positive samples in our study. In 11 samples, $C$. difficile was cultured only on CCFA (11.9\%), in nine samples only on CDSB (9.6\%), and in none of the samples on CDSA. Highest colony counts compared with the other agars were found on

Table 1. Evaluation of the C. difficile-specific FISH probe

\begin{tabular}{|llcc|}
\hline Strain & \multicolumn{1}{c}{ Source $^{\star}$} & Result with Cd-198 m probe & Result with EUB probe \\
\hline Clostridium difficile & ATCC 700057 & + & + \\
Clostridium difficile & ATCC 43255 & + & + \\
Clostridium glycolicum & CI & - & + \\
Clostridium histolyticum & DSM 2158 & - & + \\
Clostridium perfringens & ATCC 13125 & - & + \\
Clostridium sordellii & DSM 2141 & - & + \\
Clostridium sporogenes & CI & - & + \\
Clostridium tertium & INSTAND & - & + \\
Eggerthella lenta & ATCC 43055 & - & + \\
Bacillus cereus & CI & - & + \\
Bacillus mycoides & INSTAND & - & + \\
Paenibacillus polymyxa & ATCC 43865 & - & + \\
Lactobacillus acidophilus & CI & - & + \\
\end{tabular}

${ }^{*} \mathrm{CI}$, Clinical isolate (identification confirmed by $16 \mathrm{~S}$ rRNA gene sequencing); INSTAND, external quality control strain from INSTAND, WHO Collaborating Centre for Quality Assurance and Standardization in Laboratory Medicine. 
Table 2. Detection of $C$. difficile on the three selective agars

The colony count category was defined for each culture-positive sample as follows: Highest, highest numbers (determined semi-quantitatively as described in the text) on the respective agar compared with the other agars; - 1, one category less than in the agar with the highest colony count (for instance, many compared with abundant); $-2,-3$ and -4 , two, three or four categories less than in the agar with the highest colony count (for instance rare, very rare or negative compared with abundant).

\begin{tabular}{|lcccccc|}
\hline \multirow{2}{*}{ Growth on: } & \multirow{2}{*}{ No. $(\%)$ positive $(\boldsymbol{n}=\mathbf{9 4})$} & \multicolumn{5}{c|}{ No. with colony count category: } \\
\cline { 3 - 6 } & & Highest & $-\mathbf{1}$ & $\mathbf{- 2}$ & $\mathbf{- 3}$ & $\mathbf{- 4}$ \\
\hline CCFA & $85(90.4)$ & 66 & 19 & 5 & 3 & 1 \\
CDSB & $79(84.0)$ & 45 & 29 & 12 & 5 & 3 \\
CDSA & $40(42.6)$ & 17 & 26 & 14 & 25 & 12 \\
\hline
\end{tabular}

CCFA followed by CDSB (Table 2). With regard to the selectivity of the agars, concomitant growth of stool flora was evaluated. The categories of many or abundant colonies were found in $95.7 \%$ of CCFA samples (90/94), $88.3 \%$ of CDSB samples $(83 / 94)$ and $92.6 \%$ of CDSA samples (87/94). Overall, there was no notable difference in selectivity among the three agars.

With regard to biochemical identification of the toxigenic isolates, API ID32A and RapID ANAII correctly identified 97.9 and $93.6 \%$ of the isolates, respectively (Table 3). For the remaining isolates, the tests did not reveal any identification result. In three samples, suspicious colonies were finally identified as Clostridium glycolicum by sequencing, but API ID32A misidentified one and RapID ANAII two of these isolates as $C$. difficile. The FISH assay correctly identified all isolates of $C$. difficile and was negative in the three C. glycolicum strains. In addition, FISH was performed in three samples with suspicious colonies directly from the primary CCFA or CDSB, giving positive results.

In conclusion, when using a single agar, CCFA is most sensitive for detection of toxigenic $C$. difficile from stool samples. The selective composition of the new agars CDSA and CDSB did not improve the detection rate. CDSB is a valuable adjunct to CCFA, as it further increases the detection rate. This may be caused by its additional content of selecting substances, such as amphotericin, neutral red and cholic acid. The use of CDSA does not offer advantages over the other media. Although the addition of bile salts has been shown to increase the recovery of $C$. difficile (Nerandzic \& Donskey, 2009; Wilson et al., 1982), CCFA, which did not contain additional cholic acid, showed the highest sensitivity in our study. It may be speculated that the fructose in the medium enhanced selectivity, but due to the different composition of the three media, the improved performance could not be related to one particular ingredient. With regard to the selecting antibiotics, a reduced cycloserine concentration of $0.25 \mathrm{~g} \mathrm{l}^{-1}$ has been shown to be less efficient than higher concentrations (Mundy et al., 1995; Nerandzic \& Donskey, 2009). Whilst CDSB and CDSA used in this study contained only $0.25 \mathrm{~g}$ cycloserine $1^{-1}$, the addition of substances such as amphotericin and neutral red in CDSB and neutral red in CDSA probably improved the recovery rate. The selective agars evaluated in this study cost approximately US $\$ 0.75$ for CDSA, US $\$ 1$ for CCFA and US $\$ 1.70$ for CDSB per plate. Combined use of CDSB and CCFA agar thus costs about US $\$ 2.7$.

Although the morphology and odour of $C$. difficile colonies is quite characteristic, confusion with C. glycolicum occurs, stressing the necessity for confirmatory identification tests in suspicious isolates. As published previously (Celig \&

Table 3. Comparison of identification techniques for toxigenic C. difficile

\begin{tabular}{|lccc|}
\hline & API ID32A & RapID ANAII & FISH \\
\hline No. $(\%)$ of C. difficile identified correctly & $92 / 94(97.9)$ & $88 / 94(93.6)$ & $94 / 94(100)$ \\
No. $(\%)$ of non- . difficile misidentified & $1 / 3(33.3)$ & $2 / 3(66.7)$ & $0 / 3(0)$ \\
Total assay time & $4.5 \mathrm{~h}$ & $4.5 \mathrm{~h}$ & $45 \mathrm{~min}$ \\
Hands-on time & $10 \mathrm{~min}$ & $10 \mathrm{~min}$ & $10 \mathrm{~min}$ \\
Required inoculum & $3 \mathrm{ml}$, McFarland 4 & $1 \mathrm{ml}$, McFarland 3 & Minimum of one colony \\
Assay costs & $\sim$ US $\$ 4$ & $\sim$ US $\$ 4$ & $\sim$ US\$0.5 $\dagger$ \\
\end{tabular}

${ }^{*}$ Not including the fluorescence microscope and slide heater (for FISH) and software licences (for API and RapID).

$\dagger$ Including the costs of the probes, buffers and slide. 
Schreckenberger, 1991; Karachewski et al., 1985; Marler et al., 1991) and confirmed in our study, biochemical tests are not absolutely reliable in the identification of clostridia. Therefore, we aimed to find a rapid and reliable identification method, and described here a new FISH assay that can be carried out from a single colony directly from the selective agar plate. FISH probes for C. difficile have already been published (Fallani et al., 2006; Milinovich et al., 2007); however, those assays were timeconsuming, and the probes were not tested on non-target organisms except for one strain of Clostridium bifermentans (Fallani et al., 2006) and were not evaluated for detection of $C$. difficile in patients with suspected CDAD. In the current study, the rapid FISH assay correctly identified all C. difficile isolates by bright red fluorescence with the specific probe and showed no cross-reaction to related species. In addition, the FISH assay was cheap, rapid to perform and required a hands-on time of only $10 \mathrm{~min}$ (Table 3), thus allowing species identification and toxin detection within the same day.

In conclusion, the culture of stool samples on CCFA and CDSB followed by identification of suspicious isolates by FISH and toxin detection by real-time PCR represents a fast, sensitive and reliable approach for the detection of toxigenic $C$. difficile in stool samples, enabling strain typing, resistance testing and further epidemiological investigations.

\section{REFERENCES}

Amann, R. I., Binder, B. J., Olson, R. J., Chisholm, S. W., Devereux, R. \& Stahl, D. A. (1990). Combination of $16 \mathrm{~S}$ rRNA-targeted oligonucleotide probes with flow cytometry for analyzing mixed microbial populations. Appl Environ Microbiol 56, 1919-1925.

Barbut, F., Delmee, M., Brazier, J. S., Petit, J. C., Poxton, I. R., Rupnik, M., Lalande, V., Schneider, C., Mastrantonio, P. \& other authors (2003). A European survey of diagnostic methods and testing protocols for Clostridium difficile. Clin Microbiol Infect 9, 989-996.

Blossom, D. B. \& McDonald, L. C. (2007). The challenges posed by reemerging Clostridium difficile infection. Clin Infect Dis 45, 222-227.

Brazier, J. S. (1993). Role of the laboratory in investigations of Clostridium difficile diarrhea. Clin Infect Dis 16, S228-S233.

Brazier, J. S. (1998). The diagnosis of Clostridium difficile-associated disease. J Antimicrob Chemother 41, 29-40.

Burckhardt, F., Friedrich, A., Beier, D. \& Eckmanns, T. (2008). Clostridium difficile surveillance trends, Saxony, Germany. Emerg Infect Dis 14, 691-692.

Celig, D. M. \& Schreckenberger, P. C. (1991). Clinical evaluation of the RapID-ANA II panel for identification of anaerobic bacteria. J Clin Microbiol 29, 457-462.

Delmee, M., Van Broeck, J., Simon, A., Janssens, M. \& Avesani, V. (2005). Laboratory diagnosis of Clostridium difficile-associated diarrhoea: a plea for culture. J Med Microbiol 54, 187-191.

Fallani, M., Rigottier-Gois, L., Aguilera, M., Bridonneau, C., Collignon, A., Edwards, C. A., Corthier, G. \& Dore, J. (2006). Clostridium difficile and Clostridium perfringens species detected in infant faecal microbiota using 16S rRNA targeted probes. J Microbiol Methods 67, 150-161.
Fenner, L., Widmer, A. F., Goy, G., Rudin, S. \& Frei, R. (2008). Rapid and reliable diagnostic algorithm for detection of Clostridium difficile. J Clin Microbiol 46, 328-330.

George, W. L., Sutter, V. L., Citron, D. \& Finegold, S. M. (1979). Selective and differential medium for isolation of Clostridium difficile. J Clin Microbiol 9, 214-219.

Gerding, D. N., Olson, M. M., Peterson, L. R., Teasley, D. G., Gebhard, R. L., Schwartz, M. \& Lee, T. J. (1986). Clostridium difficile-associated diarrhea and colitis in adults. A prospective case-controlled epidemiologic study. Arch Intern Med 146, 95-100.

Greisen, K., Loeffelholz, M., Purohit, A. \& Leong, D. (1994). PCR primers and probes for the 16S rRNA gene of most species of pathogenic bacteria, including bacteria found in cerebrospinal fluid. J Clin Microbiol 32, 335-351.

Karachewski, N. O., Busch, E. L. \& Wells, C. L. (1985). Comparison of PRAS II, RapID ANA, and API 20A systems for identification of anaerobic bacteria. J Clin Microbiol 21, 122-126.

Kuijper, E. J., Coignard, B. \& Tull, P. (2006). Emergence of Clostridium difficile-associated disease in North America and Europe. Clin Microbiol Infect 12, 2-18.

Kuijper, E. J., Coignard, B., Brazier, J. S., Suetens, C., Drudy, D., Wiuff, C., Pituch, H., Reichert, P., Schneider, F. \& other authors (2007). Update of Clostridium difficile-associated disease due to PCR ribotype 027 in Europe. Euro Surveill 12, E1-E2.

Manz, W., Amann, R., Ludwig, W., Wagner, M. \& Schleifer, K. H. (1992). Phylogenetic oligodeoxynucleotide probes for the major subclasses of proteobacteria: problems and solutions. Syst Appl Microbiol 15, 593-600.

Marler, L. M., Siders, J. A., Wolters, L. C., Pettigrew, Y., Skitt, B. L. \& Allen, S. D. (1991). Evaluation of the new RapID-ANA II system for the identification of clinical anaerobic isolates. J Clin Microbiol 29, 874-878.

McDonald, L. C., Killgore, G. E., Thompson, A., Owens, R. C., Kazakova, S. V., Sambol, S. P., Johnson, S. \& Gerding, D. N. (2005). An epidemic, toxin gene-variant strain of Clostridium difficile. $N$ Engl J Med 353, 2433-2441.

Milinovich, G. J., Trott, D. J., Burrell, P. C., Croser, E. L., Al Jassim, R. A., Morton, J. M., van Eps, A. W. \& Pollitt, C. C. (2007). Fluorescence in situ hybridization analysis of hindgut bacteria associated with the development of equine laminitis. Environ Microbiol 9, 2090-2100.

Mundy, L. S., Shanholtzer, C. J., Willard, K. E., Gerding, D. N. \& Peterson, L. R. (1995). Laboratory detection of Clostridium difficile. A comparison of media and incubation systems. Am J Clin Pathol 103, 52-56.

Nerandzic, M. M. \& Donskey, C. J. (2009). Effective and reduced-cost modified selective medium for isolation of Clostridium difficile. J Clin Microbiol 47, 397-400.

Peterson, L. R., Kelly, P. J. \& Nordbrock, H. A. (1996). Role of culture and toxin detection in laboratory testing for diagnosis of Clostridium difficile-associated diarrhea. Eur J Clin Microbiol Infect Dis 15, 330336.

Reller, M. E., Lema, C. A., Perl, T. M., Cai, M., Ross, T. L., Speck, K. A. \& Carroll, K. C. (2007). Yield of stool culture with isolate toxin testing versus a two-step algorithm including stool toxin testing for detection of toxigenic Clostridium difficile. J Clin Microbiol 45, 3601-3605.

van den Berg, R. J., Bruijnesteijn van Coppenraet, L. S., Gerritsen, H. J., Endtz, H. P., van der Vorm, E. R. \& Kuijper, E. J. (2005). Prospective multicenter evaluation of a new immunoassay and real-time PCR for rapid diagnosis of Clostridium difficile-associated diarrhea in hospitalized patients. J Clin Microbiol 43, 5338-5340.

Wilson, K. H., Kennedy, M. J. \& Fekety, F. R. (1982). Use of sodium taurocholate to enhance spore recovery on a medium selective for Clostridium difficile. J Clin Microbiol 15, 443-446. 